\title{
STRATEGI PENERAPAN DOMAIN AFEKTIF DI LINGKUP PERGURUAN TINGGI
}

\author{
Soetam Rizky Wicaksono (soetam.rizky@machung.ac.id)
}

\begin{abstract}
The application of affective education for college student can not be explicitly done by lecturers or parents alone, but needs a special strategy in order to have a significant impact on their character development. Based on experience in the relevant fields, the impact of affective education is often overlooked by teachers and researchers because they thought the affective domain is very difficult to measure and highly dependent on other factors. This paper presents some implementation strategies based on the affective domain of literature review to find a strategy to implement the affective domain for college student groups. The results of this study is expected to be a foundation for future empirical research.
\end{abstract}

Keywords: affective domain, higher education, application strategies

Penerapan pendidikan afektif di perguruan tinggi haruslah dilakukan melalui pendekatan yang khusus, artinya tidak dapat disamakan dengan pendekatan pendidikan afektif bagi kelompok remaja yang duduk di tingkat pendidikan dasar dan menengah, karena anak remaja yang dianggap 'belum dewasa' masih dapat dikendalikan secara penuh oleh orang tua maupun guru yang merupakan faktor afektif terbesar dalam hidup mereka (Slavin, 2006: 50), sehingga penerapan ranah afektif di dalam proses pendidikan terasa akan lebih mudah. Sedangkan bagi kelompok mahasiswa yang dianggap sudah dewasa, penerapan ranah afektif harus melalui strategi khusus agar dapat memberikan dampak yang nyata bagi perjalanan hidup selanjutnya sebagai warga masyarakat.

Dalam prakteknya, dampak domain afektif di bidang pendidikan lebih sering diabaikan oleh para peneliti. Hal ini disebabkan karena mereka beranggapan bahwa domain afektif sangat sulit diukur dan memiliki ketergantungan dengan factor-faktor lain seperti faktor ekonomi, politik, sosialbudaya serta faktor psikologis atau kehidupan pribadi (Lynch, Baker \& Lyons, 2009: 16-17). Di pihak lain, domain afektif sesungguhnya memiliki pengaruh yang sangat signifikan terhadap domain kognitif (Krathwohl, Bloom \& Masia, 1964:49-50), sehingga luaran dari penerapan domain afektif sangat dibutuhkan dalam proses belajar mengajar.

Makalah yang merupakan hasil kajian pustaka ini menyajikan beberapa strategi penerapan domain afektif di lingkungan mahasiswa perguruan tinggi, khususnya dalam mengoptimalkan luaran proses belajar dalam lingkup domain afektif. Meskipun demikian, strategi maupun deskripsi tentang faktor-faktor yang berpengaruh di dalam penerapan domain afektif bagi kelompok mahasiswa perguruan tinggi yang terdapat dalam makalah ini masih perlu diverifikasi secara empiris, karena kajian yang disajikan dalam makalah ini mungkin akan berbeda dalam situasi dan kondisi yang berbeda.

\section{Taksonomi Bloom dalam Kaitannya dengan Pendidikan Afektif}

Sejak disusunnya taksonomi oleh Benyamin Bloom pada tahun 1956, maka tujuan pendidikan dibagi ke dalam tiga domain, yaitu: (a) Ranah Kognitif memuat perilaku-perilaku yang menekankan aspek intelektual, seperti pengetahuan, pemahaman, dan keterampilan berpikir, (b) Ranah Afektif memuat tentang perilaku-perilaku yang menekankan pada aspek perasaan dan emosi, 
seperti minat, sikap, apresiasi, dan penyesuaian diri, dan (c) Ranah Psikomotor berisi perilakuperilaku yang menekankan aspek keterampilan motorik seperti menari, menggambar, menggunakan komputer, dan mengoperasikan mesin. Domain afektif menurut taksonomi Bloom memiliki beberapa tingkatan, yaitu: receiving (attending), responding, valuing, organizing, dan characterization by a value atau value complex (Krathwohl, Bloom \& Masia, 1964: 176-185). Secara rinci domain afektif memiliki tingkatan-tingkatan sebagai berikut (Tabel 1).

Table 1. Tingkatan-tingkatan Domain Afektif menurut Taksonomi Bloom

\begin{tabular}{|c|c|}
\hline Tingkatan & Sub-tingkatan \\
\hline Receiving (attending) & $\begin{array}{l}\text { - Awareness } \\
\text { - Willing to receive } \\
\text { - Controlled (selected attention) }\end{array}$ \\
\hline Responding & $\begin{array}{l}\text { - acquiescence in responding, } \\
\text { - willingness to respond } \\
\text { - satisfaction in response. }\end{array}$ \\
\hline Valuing & $\begin{array}{l}\text { - penerimaan terhadap nilai-nilai yang dianut (acceptance of value } \\
\text { - } \text { preferensi nilai } \\
\text { - komitmen }\end{array}$ \\
\hline Organization & $\begin{array}{l}\text { - conceptualization of a value } \\
\text { - organization of a value system. }\end{array}$ \\
\hline $\begin{array}{l}\text { Characterization by value (value } \\
\text { complex) }\end{array}$ & $\begin{array}{l}\text { - generalized set } \\
\text { - characterization }\end{array}$ \\
\hline
\end{tabular}

Pada tingkatan receiving (attending), fokus pembelajaran adalah pada asumsi, artinya pada saat pembelajar diberi penjelasan tentang sebuah fenomena atau diberi stimulus, maka pembelajar akan mau menerima keberadaan fenomena atau stimulus tersebut. Terdapat 3 (tiga) sub tingkatan, yaitu kesadaran (awareness), kemauan untuk menerima (willingness to receive), dan perhatian tertentu (selected attention).

Kesadaran agak berbeda dengan perilaku kognitif, terutama pada saat merespon sebuah stimulus. Di dalam perilaku kognitif, pembelajar dapat mengungkapkan respon atas sebuah stimulus, sedangkan di sub level ini pembelajar hanya menerima stimulus tersebut tanpa ada kewajiban untuk menyatakan sebuah respon. Sebagai contoh, pembelajar hanya memperhatikan lingkungan sekitar yang dianggap menarik seperti perabot kelas, bangunan sekolah tanpa memberikan komentar.

Pada sub level kemauan untuk menerima, pembelajar hanya memiliki kemauan untuk menerima stimulus yang diberikan oleh pengajar, sehingga pembelajar hanya berada dalam keadaan pasif menerima dengan cara memperhatikan apa yang diberikan kepadanya. Contoh di sub level ini adalah pada saat pembelajar telah bersedia untuk memperhatikan apa yang diucapkan oleh sang pengajar, meski tidak harus mampu memahami apa yang sedang diucapkan, tetapi sudah terdapat kemauan untuk berusaha fokus kepada apa yang sedang dikatakan atau sedang diterangkan pada saat itu.

Pada sub level yang ke-3 yaitu perhatian tertentu (selected attention), pembelajar telah mampu menerima stimulus secara sadar sehingga mampu memilah dengan baik stimulus yang diberikan oleh pengajar di luar stimulus yang ada pada saat itu. Sebagai contoh, si pembelajar telah mampu memilah antara satu rumus dengan rumus yang lain dalam sebuah pelajaran di bidang sains.

Pada tingkatan menanggapi (responding), fokus pembelajaran adalah pada respon individu terhadap suatu fenomena, jadi lebih dari hanya sekadar memperhatikan. Pada tingkatan ini seorang 
pengajar dapat melihat secara langsung ketertarikan si pembelajar pada materi yang sedang diajarkan pada saat itu. Pada tingkatan ini, terdapat 3 (tiga) sub tingkatan, yaitu: acquiescence in responding, willingness to respond, dan satisfaction in response. Pada subtingkatan persetujuan dalam merespon (acquiescence in respondin), pembelajar mulai menunjukkan kepatuhan terhadap peraturan yang diterapkan atau menunjukkan reaksi terhadap kewajiban yang disampaikan oleh pengajar. Demikian pula, pada willingness to respond si pembelajar telah menunjukkan sikap sukarela dalam melaksanakan tugas yang diberikan oleh pengajar. Sedangkan pada sub-tingkatan satisfaction in response, pengajar dapat melihat secara jelas kepuasan dan rasa senang yang ditunjukkan oleh para pembelajar secara eksplisit.

Pada tingkatan valuing, pembelajar akan menunjukkan komitmennya berdasarkan nilai yang dianutnya yang selanjutnya akan menuntun perilaku pembelajar. Kondisi ini sangat berbeda dengan konsep motivasi eksternal yang hanya mengarah kepada kepatuhan. Terdapat 3 (tiga) sub tingkatan valueing, yaitu penerimaan terhadap nilai-nilai yang dianut (acceptance of value), preferensi nilai, dan komitmen. Pada sub-tingkatan acceptance of value, pembelajar telah memiliki keyakinan bahwa dirinya telah memiliki nilai-nilai tertentu dalam dirinya dan memiliki kemauan untuk dapat diidentifikasi oleh orang lain berdasarkan keyakinan tersebut. Misalnya, seorang siswa memiliki keyakinan bahwa dirinya dapat bertoleransi dengan banyak orang yang berasal dari berbagai daerah asal. Pada subtingkatan preference of value, pembelajar tidak hanya yakin pada nilai yang telah dia miliki, namun juga berusaha untuk mempertahankan nilai-nilai tersebut. Sedangkan pada sub-tingkatan commitment, seseorang tidak hanya percaya terhadap suatu nilai tetapi juga berusaha berkomitmen kepada nilai tersebut sehingga pada akhirnya akan menjadi sebuah motivasi dalam melakukan suatu tindakan.

Pada tingkatan organisasi (organization), pembelajar sudah sampai pada tahapan mempercayai nilai-nilai tertentu, selanjutnya ia akan dihadapkan pada lebih dari satu nilai atau beberapa nilai yang harus dipercayainya. Pada tingkatan ini, pembelajar mulai mengorganisasi nilainilai tersebut dan mencari hubungan antara satu nilai dengan nilai yang lain, dan selanjutnya berusaha menemukan nilai yang menurutnya paling dominan. Organization memiliki 2(dua) sub tingkatan, yaitu: conceptualization of a value dan organization of a value system.

Sebagai lanjutan dari level sebelumnya, maka pada conceptualization of a value, seorang pembelajar mulai merelasikan nilai-nilai yang dia miliki dan berusaha mencari nilai mana yang seharusnya dia pegang teguh. Selanjutnya, setelah melakukan abstraksi dari nilai yang dia miliki pada sub-tingkatan organization of a value system, pembelajar akan berusaha mengorganisasi seluruh nilai yang ia temukan.

Pada tingkatan yang terakhir yaitu characterization by value set atau value complex, pembelajar dianggap telah memiliki nilai yang kuat di dalam dirinya, maka ia akan berusaha melakukan generalisasi terhadap perilakunya dan mengintegrasikan keyakinan, ide dan tingkah laku menjadi sebuah filosofi hidup. Terdapat dua sub level yaitu: generalized set dan characterization. Pada sub-tingkatan generalized set, seorang pembelajar telah mampu bersikap konsisten dari dalam diri sendiri atau internal berdasarkan nilai-nilai yang telah ia miliki. Sedangkan sub-tingkatan characterization merupakan puncak dari proses internalisasi. Karenanya, pada sub level ini pembelajar telah mampu memiliki filosofi pribadi yang kuat dan konsisten. 


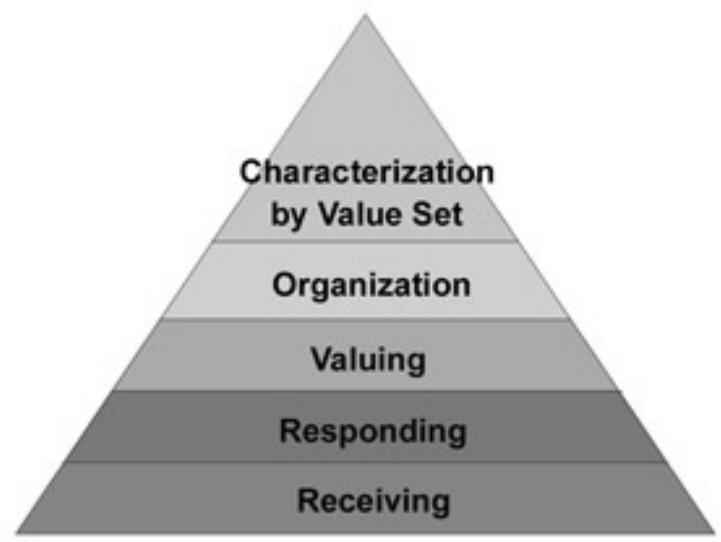

Gambar 1. Skema domain afektif (sumber: http://classweb.gmu.edu/ndabbagh/Resources/Resources2/krathstax.htm)

\section{Hubungan antara Domain Afektif dan Domain Kognitif}

Menurut Bloom dan Masia (1964: 49), hubungan antara domain afektif dengan domain kognitif dapat dijelaskan dalam rangkuman berikut.

- Untuk dapat mencapai tingkatan knowledge di domain kognitif, maka harus didahului oleh level receiving di dalam domain afektifnya agar siswa dapat benar-benar memahami materi.

- Untuk mencapai tingkatan pemahaman pada domain kognitif, dibutuhkan hasil signifikan dari responding, yang berada di domain afektif. Sebab tanpa adanya respon yang baik dari pembelajar, maka tingkat pemahaman dalam domain kognitif tidak akan pernah tercapai.

- Untuk mencapai tingkatan aplikasi pada domain kognitif, seorang pembelajar harus terlebih dulu memiliki nilai yang ada di dalam dirinya dan secara sukarela menerapkan secara langsung (level valuing) agar dapat mengaplikasikan pemahaman yang telah diperoleh secara baik.

- Untuk mencapai tingkatan analisa pada domain kognitif, seorang pembelajar harus terlebih dulu mencapai level conceptualization pada domain afektif, karena seseorang tidak mungkin dapat melakukan analisa tanpa daya konseptualisasi nilai yang telah dia miliki. Karena itu, pembelajar harus mencapai tingkatan conceptualization berdasarkan pengetahuan yang telah dimiliki.

- Pada tingkatan evaluasi pada domain kognitif, seorang pembelajar seharusnya telah mampu mencapai tahapan characterization pada domain afektif. Sebab dengan adanya karakter yang kuat di dalam pribadinya, seorang pembelajar akan dapat memilah pengetahuan yang ada di dalam dirinya dan kemudian menerapkan ke masalah yang dia hadapi.
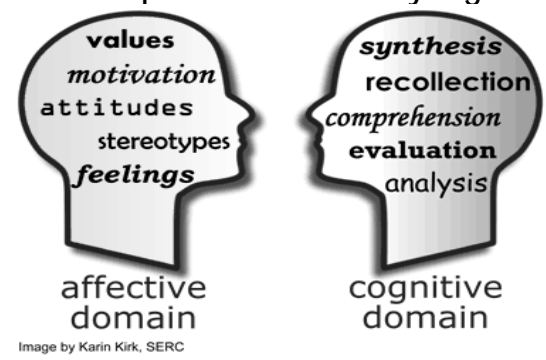

Gambar 2. Hubungan antara domain afektif dan domain kognitif (sumber: http://en.wikipedia.org/wiki/BloomTaxonomy) 


\section{Strategi Penerapan Domain Afektif}

Terdapat empat isu yang perlu diperhatikan dan sangat berpengaruh dalam menerapkan ranah afektif dalam proses perkuliahan di tingkat perguruan tinggi, yaitu: (i) kenyamanan lingkungan belajar, (ii) attitudinal, (iii) situasi kelas yang demokratis, dan (iv) pembentukan interaksi sosial berbasis komunitas. Yang dimaksud dengan kenyamanan lingkungan belajar adalah lingkungan belajar yang nyaman bagi mahasiswa tidaklah sama dengan definisi "nyaman" untuk siswa pendidikan dasar menengah. Lingkungan kampus yang dipenuhi suasana dengan kesan high tech, perlengkapan perkuliahan yang modern (terlepas dari kesan kuno dan "menyedihkan") serta bersih terbukti sangat mempengaruhi suasana emosi para mahasiswa, khususnya para mahasiswa di golongan rookie (Burgan, 2006: 28-29).

Attitudinal yang di dalam lingkungan kampus perguruan tinggi diterjemahkan sebagai identitas lingkungan seperti jaket, emblem, kaos maupun topi terbukti dapat membantu seorang mahasiswa membangkitkan perasaan-perasaan yang masuk ke ranah afektif. Terbukti pula bahwa pada saat aspek dalam ranah afektif dapat dibangkitkan, maka dengan segera aspek yang terdapat dalam ranah kognitif akan dapat dimunculkan dengan mudah di dalam proses belajar mengajar (Kamradt \& Kamradt, 1999: 570).

Suasana demokratis di dalam kelas dapat diwujudkan dengan mengasumsikan bahwa pengambilan keputusan dilakukan bersama dengan tujuan agar suasana kelas dapat lebih baik dan meningkatkan tanggung jawab secara bersama-sama, serta menganggap bahwa hasil keputusan rapat kelas adalah pemimpin tertinggi (Lickona, 1999:603). Adanya situasi kelas yang demokratis diharapkan dapat membawa perasaan peserta belajar menjadi lebih nyaman karena merasa lebih dihargai sehingga dapat membantu mereka memecahkan masalahnya sendiri karena dianggap lebih bertanggungjawab dan dewasa (Lickona, 1999: 604). Selain itu, dengan situasi kelas yang demokratis akan menyebabkan para siswa "terpaksa" bekerja sama satu sama lain atau juga lazim disebut sebagai cooperative learning. Hal ini didukung oleh asumsi bahwa salah satu tujuan dari cooperative learning adalah untuk meningkatkan penghargaan diri melalui perasaan dihormati dan dihargai oleh orang lain dalam sebuah lingkungan (Joyce, Weil \& Calhoun, 2009: 302)

Interaksi sosial berbasis komunitas merupakan salah satu faktor penting dalam penerapan ranah afektif. Hal ini terlihat dengan makin maraknya situs jejaring sosial yang menyeret mahasiswa menjadi generasi Y super aktif merupakan dampak empiris bahwa interaksi sosial berbasis komunitas. Hasil penelitian oleh Innes dan Ally (2004) menyatakan bahwa pembelajar dewasa akan sangat terbantu luaran afektifnya dengan adanya interaksi sosial yang berbasis pada refleksi dan memberikan umpan balik satu sama lain.

Berdasarkan kajian teoritis di atas dapat dijelaskan 4 buah strategi khusus yang dianggap dapat mendukung optimalisasi luaran proses belajar khususnya di ranah afektif yaitu: (i) penerapan pembelajaran yang bersifat asynchronous, (ii) penerapan pembelajaran berbasis web atau online learning, (iii) penerapan kolaborasi dosen-mahasiswa yang bersifat kompetitif, dan (iv) penerapan pendidikan yang membuat mahasiswa menjadi longlife learner.

Menerapkan pembelajaran yang bersifat asynchronous atau dapat bersifat timbal balik tanpa harus menunggu respon dari salah satu pihak. Ini berarti bahwa di dalam penerapannya, mahasiswa dapat melakukan proses pembelajaran dengan waktu yang tidak ditentukan dan sesuai selera. Secara umum, strategi ini biasanya diterapkan di dalam pembelajaran berbasis web dan telah terbukti dapat meningkatkan luaran di domain afektif secara signifikan. Luaran domain afektif yang dicapai adalah meningkatnya level respon yang ditandai dengan adanya kemauan dan kepuasan dalam merespon sumber belajar secara signifikan (Cleveland-Innes \& Ally, 2004: 27). 
Menerapkan pembelajaran berbasis web atau online learning dengan mengubah model dari strategi pembelajaran yang bersifat konvensional ke lebih moderat. Sebab dengan menerapkan pembelajaran berbasis web atau e-learning namun tidak mengubah strategi pembelajaran konvensional yang lebih terpusat ke pengajar, maka luaran yang diharapkan tidak akan tercapai (Mc Glone, 2011: 8). Akan tetapi dengan pengubahan strategi pembelajaran di dalam e-learning dapat menyebabkan pembelajar berada di level valuing pada domain afektif khususnya di sub level komitmen. Sebagai contoh, dengan menerapkan model crowdsourcing berbasis wiki pada e-learning dapat secara signifikan meningkatkan partisipasi mahasiswa di dalam e-learning karena adanya keterikatan layaknya yang didapat mahasiswa di dalam situs jejaring sosial. Hal tersebut didukung adanya kompetisi secara sehat dan reward yang bersifat sebagai reinforcement bagi mahasiswa (Borst, 2010: 131). Selain itu dapat menjamin luaran di domain afektif khususnya di level penerimaan (receiving), yaitu pada saat mahasiswa dapat menjadi toleran terhadap perbedaan sekaligus berada di level willingness to receive sebagai salah satu modal penting bagi seorang pembelajar untuk menuju ke level knowledge di dalam domain kognitif.

Penerapan kolaborasi dosen-mahasiswa yang bersifat kompetitif dapat pula membantu luaran di domain afektif secara optimal. Strategi pembelajaran dengan melakukan kolaborasi antar pembelajar saat ini sudah dianggap sebagai sesuatu yang telah sangat lazim, namun demi mencapai luaran yang optimal, dosen dapat menerapkan strategi yang keluar dari comfort zone dengan mengajak mahasiswa berkolaborasi bersama-sama (Borbye, 2010: Ch. 3, 8-9). Kolaborasi dalam konteks ini dapat dimasukkan ke dalam lingkup cooperative learning, sebab di dalam implementasi cooperative learning dapat menghasilkan tiga butir penting yakni pengupayaan terhadap tujuan oleh si pembelajar, hubungan yang positif dengan sesama serta lebih sehat secara psikologis (Johson \& Johnson, 1996: 787). Kolaborasi tersebut dapat berupa riset maupun dalam tugas yang berkaitan dengan proses pembelajaran. Namun di dalam kolaborasi tersebut wajib disertakan proses kompetisi secara sehat dengan penghargaan yang dapat mengikat mahasiswa secara emosional demi mendapatkan luaran domain afektif di level penerimaan, khususnya sub level selected attention yang berarti stimulus dari mahasiswa tersebut dapat meningkat sehingga respon yang diterima juga meningkat.

Menjadi mahasiswa sebagai longlife learner pembelajaran diterima tidak hanya di dalam kelas saat perkuliahan berlangsung, tetapi juga harus melakukan pencarian ilmu di luar jam pelajaran dengan sumber belajar yang bervariasi. Konsep pencarian sumber pembelajaran yang luas dan mandiri dan melakukan pembelajaran layaknya sebuah benih tanaman yang terus tumbuh dan membesar disebut juga sebagai self-science (Mc Cown \& Mc Cormick, 1999: 544). Meski dalam penelitian Mc Cown dan Mc Cormick (1999), self-science diarahkan kepada pendidikan anak sekolah dasar, namun dengan konsep yang sama konsep yang telah terbukti berhasil membangkitkan luaran domain afektif secara nyata tersebut juga dapat diterapkan di lingkup perguruan tinggi. Dalam strategi ini, pembelajar diajak untuk berkompetisi dengan diri sendiri dalam memecahkan sebuah masalah, membangkitkan emosi dan perasaan yang jujur dari dalam diri sendiri namun tetap dibantu oleh pengajar pada saat si pembelajar telah merasakan keterbatasan di dalam dirinya (Mc Cown \& Mc Cormick, 1999: 548). Hal tersebut berarti bahwa strategi ini dapat membantu luaran domain afektif di level valuing, khususnya di sub level penerimaan nilai yang berarti bahwa seseorang akhirnya dapat menerima posisi dirinya dan posisi orang lain yang memiliki level lebih baik dari dirinya (Krathwohl, Bloom \& Masia, 1964: 181). 


\section{PENUTUP}

Faktor-faktor yang berpengaruh secara signifikan dalam penerapan domain afektif bagi kelompok mahasiswa antara lain adalah kenyamanan lingkungan belajar, attitudinal, situasi kelas yang demokratis, dan pembentukan interaksi sosial berbasis komunitas.

Strategi yang dapat diterapkan di dalam mengoptimalkan luaran domain afektif di lingkup perguruan tinggi adalah: (i) menerapkan pembelajaran yang bersifat asynchronous, menerapkan pembelajaran berbasis web atau online learning dengan mengubah model dari strategi pembelajaran yang bersifat konvensional ke lebih moderat, (iii) menciptakan kolaborasi dosen-mahasiswa yang bersifat kompetitif, dan (iv) menjadikan mahasiswa sebagai longlife learner.

Kajian di atas masih membutuhkan kajian secara empiris dengan penyesuaian terhadap situasi dan kondisi di masing-masing tempat. Meskipun telah terbukti secara ilmiah bahwa luaran domain afektif sangat berpengaruh terhadap luaran domain kognitif, tetapi luaran domain afektif masih diakui banyak peneliti sebagai sesuatu yang abstrak untuk diukur. Untuk itu, strategi yang dapat diterapkan tidak hanya terbatas pada uraian yang telah disebutkan, hanya karena keterbatasan ruang dan waktu yang menjadikan item yang dijabarkan menjadi terbatas. Sebab masih sangat banyak kajian lain yang telah dibuktikan secara ilmiah, mengungkapkan strategi-strategi lain untuk mencapai luaran di domain afektif secara lebih optimal.

Demikianlah, pada dasarnya keberadaan domain afektif di dalam dunia pendidikan memang tidak boleh serta merta diabaikan karena sifat pembelajaran yang harus memperhatikan aspek emosional guna mencapai tujuannya, sehingga meski diakui penerapannya sebagai sesuatu yang sulit, penerapan domain afektif tetap menjadi kewajiban bagi seorang pengajar di dalam proses pembelajaran.

\section{REFERENSI}

Borbye, L. (2010). Out of the comfort zone: New ways to teach, learn and assess essential professional skill. Morgan \& Claypool Publishers.

Borst, I. (2010). Understanding crowdsourcing, ERIM PhD series in research in management. Roterdam: Erasmus Universiteit Rotterdam.

Burgan, M. (2006). What ever happened to the faculty? Baltimore: John Hopkins University Press.

Innes, C.M. \& Ally, M. (2004). Affective learning outcomes in workplace training: a test of synchronous vs. asynchronous online learning environments. Canadian Journal of University Continuing Education 30 (1). Spring 2004.

Johnson, D. \& Johnson, R.T. (1996). Cooperation and the use of technology. Didalam Handbook of Research for Educational Communications and Technology (ed. David H. Jonassen). New York: MacMillan Publishing.

Joyce, B., Weil, M. \& Calhoun, E. (2009). Models of teaching (terjemahan: Model-model Pengajaran oleh Achmad Fawaid dan Ateilla Mirza). Ed. 8. Jakarta: Penerbit Pustaka Pelajar.

Kamradt, T. F. \& Elizabeth J. \& Kamradt, E.J. (1999). Structured design for attitudinal instruction dalam Instructional-design theories and models volume II (ed. Charles M. Reigeluth) p563590. Mahwah: Lawrence Erlbaum Associates.

Krathwohl, D. E, Bloom, B.S. \& Masia, B.B. (1964). Taxonomy of educational objects, the classification of educational goals. Handbook II: Affective Domain. New Jersey: Longmans. 
Lickona, T. (1999). Character Education: The Cultivation of Virtue dalam Instructional-Design Theories and Models Volume II (ed. Charles M. Reigeluth) p 594-612. Mahwah: Lawrence Erlbaum Associates.

Lynch, K., Baker, J. \& Lyons, M. (2009). Affective equality. Palgrave: Macmillan Publ.

Martin, B.L. \& Reigeluth, C.M. (1999). Affective education and the affective domain: implications for instructional-design theories and models dalam Instructional-design theories and models volume II (ed. Charles M. Reigeluth) p485-509. Mahwah: Lawrence Erlbaum Associates.

Mc Cown, K. S. \& Mc Cormick, A. H. (1999). Self-science: Emotional intelligence for children dalam Instructional-design theories and models Volume II (ed. Charles M. Reigeluth) p 537-561. Mahwah: Lawrence Erlbaum Associates.

McGlone, J. (2011). Adult learning styles and on-line educational preference. Research in higher education journal 12, 1-9.

Moore, J. (1999). Adolescent spiritual development: Stages and strategies dalam Instructional-design theories and models volume II (ed. Charles M. Reigeluth) p.613-629. Mahwah: Lawrence Erlbaum Associates.

Slavin, R. E (2006). Educational psychology (8th ed). Boston: Pearson Publ. 